\title{
Reconsolidation of a Long-Term Memory in Lymnaea Requires New Protein and RNA Synthesis and the Soma of Right Pedal Dorsal 1
}

\author{
Susan Sangha, Andi Scheibenstock, and Ken Lukowiak \\ Department of Physiology and Biophysics, Calgary Brain Institute, University of Calgary, Calgary, Alberta, Canada T2N 4N1
}

\begin{abstract}
Reconsolidation of a long-term memory (LTM) in the snail Lymnaea stagnalis can be disrupted by cooling, an RNA synthesis blocker (actinomycin D), and by specifically ablating the soma of a cell we know is a site of LTM consolidation (right pedal dorsal 1, RPeD1). Aerial respiratory behavior was conditioned operantly by applying a gentle tactile stimulus to the pneumostome area (the respiratory orifice) every time the snail began to open its pneumostome to perform aerial respiration. This resulted in a reduction of this behavior while leaving cutaneous respiration intact. One week after training one-half of the animals received a memory reactivation session, which was similar to the original training (i.e., animals received reinforcement). All animals then received $1 \mathrm{hr}$ of cooling, an injection of actinomycin D or saline, or the soma ablation procedure. This was followed by a test for savings $4 \mathrm{hr}$ or $4 \mathrm{~d}$ later, which was also similar to the original training. Only those animals that received both the memory reactivation session and the treatment showed memory impairment during the test for savings. That is, the impairment was contingent on memory reactivation. These data indicate that reconsolidation requires both new RNA and protein synthesis to stabilize a reactivated memory, and it demonstrates that the soma of RPeD1, a cell that we have shown previously to be required in the consolidation of an LTM, is necessary for reconsolidation. These data suggest that the critical molecular processes occurring during both consolidation and reconsolidation transpire in the same cell in Lymnaea.
\end{abstract}

Key words: Lymnaea; reconsolidation; learning; memory; operant conditioning; protein synthesis

\section{Introduction}

The notion that events experienced immediately before brain trauma are the ones most likely to be forgotten (Ribot, 1882) led to the consolidation hypothesis, stating that memories initially exist in a fragile form and are strengthened over time (Muller and Pilzecker, 1900). More recently, there have been accounts that a memory reenters a labile state with memory reactivation and must be reconsolidated before once again returning to a stable state. The occurrence of a reconsolidation phase was demonstrated first by Lewis in 1968 (Misanin et al., 1968) and since has been demonstrated in rodents (Przybyslawski and Sara, 1997; Nader et al., 2000; Taubenfeld et al., 2001), Limax (Yamada et al., 1992; Sekiguchi et al., 1997), chicks (Anokhin et al., 2002), and crab (Pedreira et al., 2002).

Like consolidation, cAMP response element-binding protein (CREB) also is required in the reconsolidation of a conditioned fear memory in mice (Kida et al., 2002), and there are several reports that protein synthesis is required during reconsolidation in a variety of learning paradigms (Judge and Quartermain, 1982; Nader et al., 2000; Anokhin et al., 2002; Debiec et al., 2002; Kida

\footnotetext{
Received June 5, 2003; revised July 14, 2003; accepted July 14, 2003.

This work was supported by a grant from the Canadian Institutes of Health Research to K.L. S.S. is supported by a scholarship from the Natural Sciences and Engineering Research Council. We thank the reviewers for their helpful comments.

Correspondence should be addressed to Dr. Ken Lukowiak, Department of Physiology and Biophysics, University of Calgary, 3330 Hospital Drive Northwest, Calgary, Alberta, Canada T2N 4N1. E-mail: lukowiak@ucalgary.ca. Copyright $\odot 2003$ Society for Neuroscience $\quad$ 0270-6474/03/238034-07\$15.00/0
}

et al., 2002; Milekic and Alberini, 2002; Pedreira et al., 2002). Adding these findings to the knowledge that reconsolidation has been demonstrated in evolutionarily diverse systems, there is an expectation that the molecular events involved in reconsolidation will be conserved across species.

The freshwater snail Lymnaea stagnalis serves as an excellent model in the study of learning and memory (Lukowiak et al., 2003 b). Because Lymnaea are bimodal breathers, it is possible to modulate one of its respiratory behaviors while leaving the other unaffected. More specifically, we use an operant (i.e., instrumental) conditioning paradigm to decrease the occurrence of aerial respiratory behavior (Lukowiak et al., 1996, 1998, 2000). These snails still can breathe cutaneously, and thus our procedure is not harmful to the animals.

Aerial respiration is controlled by a well characterized threeneuron central pattern generator (CPG) for which the sufficiency and necessity have been demonstrated (Syed et al., 1990, 1992). Because nondeclarative memories are defined as being stored within the same network that mediates the behavior (Milner et al., 1998), the changes induced by operant conditioning of aerial respiratory behavior must be stored within the respiratory CPG in Lymnaea. Indeed, such changes have been found in one of the three neurons that constitute the CPG, right pedal dorsal 1 (RPeD1). Neural correlates of learning and memory have been found in RPeD1 (Spencer et al., 1999, 2002); as well, the soma of $\mathrm{RPeD} 1$ has been shown to be necessary for the formation of new long-term memories (Scheibenstock et al., 2002). 
Here we demonstrate that reconsolidation of a long-term memory can be interrupted by cooling, an RNA synthesis blocker, and by ablating just the soma of the cell RPeD1. This disruption is contingent on memory reactivation; in those animals in which the memory was not reactivated, the treatments did not have any effect on memory performance. Thus new RNA and protein synthesis and the soma of RPeD1 are necessary for reconsolidation of a previously established memory.

\section{Materials and Methods}

Subjects. Lymnaea stagnalis were bred and raised in the snail facility at the University of Calgary. All snails that were used $(2.5-3.0 \mathrm{~cm})$ were maintained at room temperature $\left(23^{\circ} \mathrm{C}\right)$ and had continuous access to lettuce in their home eumoxic (i.e., normal levels of $\mathrm{O}_{2} ; 6 \mathrm{ml} \mathrm{O}_{2} / \mathrm{l}$ ) aquaria.

Operant conditioning procedure. Individually labeled snails were placed in a 11 beaker containing $500 \mathrm{ml}$ of room temperature hypoxic pond water. The water was made hypoxic $\left(<0.1 \mathrm{ml} \mathrm{O}_{2} / \mathrm{l}\right)$ by bubbling $\mathrm{N}_{2}$ through it $20 \mathrm{~min}$ before and during training. In all of the training sessions, memory reactivation sessions, and tests for savings, a gentle tactile stimulus (using a sharpened wooden applicator) was applied to the pneumostome area (the respiratory orifice) every time the snail began to open its pneumostome to perform aerial respiration. This tactile stimulus evoked only pneumostome closure; it did not cause the animal to withdraw its foot and mantle area (i.e., the whole-animal withdrawal response). Pneumostome stimulation also did not cause the snails to sink to the bottom of the beaker. The time of each attempted opening was recorded and tabulated. In all experiments the snails first were given a 10 min acclimatization period in which they could perform aerial respiration without receiving reinforcement. The onset of operant conditioning training was initiated by gently pushing the snails beneath the water surface. Between each training session and between the last training session and the test for savings, as in all of our previous experiments, snails were placed in eumoxic pond water where they were allowed to perform aerial respiration freely. We did not monitor the snails' breathing behavior during the periods they were in their eumoxic home aquaria.

In all experiments, which were done blindly, snails first were administered four $45 \mathrm{~min}$ operant conditioning sessions. The first two training sessions were given on the same day at $1 \mathrm{hr}$ apart. The next day the third and fourth training sessions were given, also $1 \mathrm{hr}$ apart. Both the memory reactivation session and the test for savings involved applying reinforcement, similar to the original training. We refer to the test for savings as such because this is the session in which the memory is being assessed for successful reconsolidation.

Yoked training procedure. Snails that received yoked training were treated in an identical manner as that outlined in Operant conditioning procedure, with one exception. During the training period the yoked snails received exactly the same number of stimuli with the use of the same pattern of stimulation as those of the operant conditioning group; however, the stimuli were not contingent on the animal making pneumostome opening movements. If the pneumostome area was not readily accessible, the stimulus was applied in the proximity of the pneumostome (Lukowiak et al., 1996, 1998, 2000, 2003a).

Operational definitions of learning and memory. We have defined memory operationally as we have done previously (Lukowiak et al., 1996, 1998, 2000, 2003a; Spencer et al., 1999, 2002). Learning was present if the number of attempted pneumostome openings in the fourth training session was significantly less than the number of attempted openings in the first training session. To be defined as memory, two criteria had to be met: (1) the number of pneumostome openings in the test for savings was significantly lower than that of the first training session, and (2) the number of pneumostome openings in the test for savings was not significantly higher than that of the last training session. If these criteria were not met, it was not designated as memory for operant conditioning.

Statistical analysis. To determine whether the experimental manipulation had an effect when compared with the control group and whether the number of attempted pneumostome openings was altered significantly as a result of operant conditioning, we performed repeated measures one-way ANOVAs, testing both a between-group factor [i.e., MR (memory recall) vs NoMR (no memory recall)] and a within-group factor (i.e., training sessions vs tests for savings) (Zar, 1999). If the ANOVA was significant $(p<0.05)$, a post hoc Scheffé's comparison was performed to show which groups and sessions were significantly different. Differences were considered to be significant if $p<0.05$.

Cooling procedure. One liter beaker filled with $500 \mathrm{ml}$ of eumoxic water was prechilled and maintained at $4^{\circ} \mathrm{C}$; it served as the cooling apparatus. We have shown previously that the cooling procedure does not affect the snails adversely and either can block or extend the memory for operant conditioning, depending on when it is applied (i.e., during or after memory consolidation, respectively) (Sangha et al., 2003b).

Injections. The RNA synthesis blocker (dissolved in saline) or saline control was injected into the hemocoel through the foot of the snail. The concentration used was $1 \mu \mathrm{g}$ of actinomycin D (RNA synthesis blocker) per milliliter of snail volume. Previously, this same concentration was used effectively in our laboratory to block the transcription process (Feng et al., 1997; van Minnen et al., 1997; Hamakawa et al., 1999). We also have demonstrated directly that this blocker inhibits protein synthesis (Feng et al., 1997; van Minnen et al., 1997) and that this particular blocker differentially affects intermediate-term (ITM) memory and long-term (LTM) memory (Sangha et al., 2003a).

We recalculated the concentration to an amount of $0.1 \mathrm{ml}$ to be injected in snails, with volumes of $3 \mathrm{ml}$. We have demonstrated previously that animals injected with actinomycin D do not show signs of sickness until $8 \mathrm{hr}$ after injection (Sangha et al., 2003a). All of the tests for savings performed in this study are within this time window (i.e., $8 \mathrm{hr}$ after injection).

Soma ablation procedure. It has been shown previously that the soma of $\mathrm{RPeD1}$ is required for LTM formation (Scheibenstock et al., 2002). The ablation procedure here was performed in the same manner as before (Scheibenstock et al., 2002). The ablation involved anesthetizing the animals with $1-3 \mathrm{ml}$ of $50 \mathrm{~mm} \mathrm{MgCl}_{2}$ that was injected through the foot. This paralyzed the snail, allowing a dorsal midline incision to be made that exposed the animal's brain. Using a fine glass hand-held microelectrode, we ablated the RPeD1 soma by gently "poking" it. The incision was small enough to allow the animal to heal without suturing. Animals began to wake from the effects of the anesthetic within several hours of the surgery.

To ensure that the soma of the proper cell indeed had been ablated, a trained individual who was unfamiliar with the experiments attempted to visualize the cell that was ablated under the microscope at the conclusion of the experiment. In all cases the cell that had been ablated could not be found.

\section{Results}

\section{Demonstration of memory $7 \mathrm{~d}$ after training}

In all of the experiments presented in this paper a particular training regimen that produces a memory that lasts at least $7 \mathrm{~d}$ was used. We use this protocol so that the memory reactivation sessions could be administered at a time after training in which robust memory normally is exhibited. Here we show that this specific procedure indeed does induce a memory lasting at least $7 \mathrm{~d}$.

Animals received either operant conditioning training $(n=$ $24)$ or yoked training $(n=15)$, as outlined in Materials and Methods. Then $7 \mathrm{~d}$ later they received a memory reactivation session followed by a test for savings $4 \mathrm{hr}$ later (Fig. 1). A memory lasting beyond $4 \mathrm{hr}$ is considered an LTM in our model system because it is dependent on both RNA and protein synthesis (Sangha et al., 2003a,b). Animals that received operant conditioning demonstrated memory, whereas yoked animals did not $\left(F_{(38,5)}=93.283 ; p<0.0001\right)$. The test for savings for animals that received yoked training was significantly higher $(p<0.01)$ than that administered to the operantly conditioned group. The test for savings for animals that received yoked training was not significantly different $(p>0.05)$ from the first training session and was significantly higher $(p<0.01)$ than the last training session. 


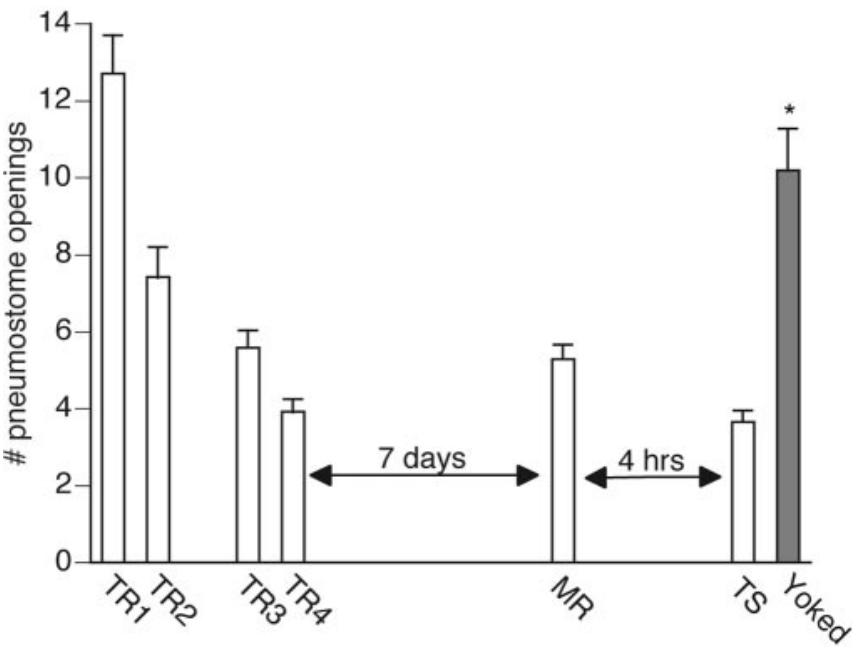

Figure 1. Four training sessions induce a $7 \mathrm{~d}$ memory. Operant training was administered (TR1-TR4) over the course of $2 \mathrm{~d}(n=24)$. Animals demonstrated memory during the memory recall (MR) session $7 \mathrm{~d}$ later. Memory was assessed again $4 \mathrm{hr}$ after MR (TS), and the animals still demonstrated memory. Animals that received yoked training did not demonstrate memory; ${ }^{*} p<0.01$ as compared with MR.

For the animals that received operant conditioning, the memory reactivation session was significantly lower $(p<0.01)$ than the first training session and not significantly different $(p>0.05)$ from the last training session, thus meeting the criteria for memory designation. The test for savings administered $4 \mathrm{hr}$ later was significantly less $(p<0.01)$ than the first training session and not significantly different $(p>0.05)$ from the last training session. Thus with this particular training regimen the animals demonstrated memory $7 \mathrm{~d}$ after training as well as showed successful memory reactivation and reconsolidation as tested $4 \mathrm{hr}$ later.

\section{Cooling can interfere with the reconsolidation process}

Cooling has been used in several laboratories as a tool to disrupt memory formation (Yamada et al., 1992; Cartford et al., 1997; Morrison and van der Kooy, 1997; Sekiguchi et al., 1997; Sangha et al., 2003b). If applied during the consolidation phase, it has been very successful in interfering with the cascade of events that lead to the formation of an ITM or LTM. We asked here whether this same technique can interfere with the reconsolidation process.

Snails $(n=33)$ received operant conditioning training as outlined in Materials and Methods. Then $7 \mathrm{~d}$ later the animals were divided randomly into two groups (Fig. 2). The first group (Fig. $2 A ; n=19$ ) received a memory reactivation session immediately followed by $1 \mathrm{hr}$ of cooling (prechilled $4^{\circ} \mathrm{C}$ water). Animals then were placed in room temperature water until the test for savings ( $4 \mathrm{hr}$ after the memory reactivation session). The second group did not receive a memory reactivation session (Fig. $2 B ; n=14$ ) but still were placed in $1 \mathrm{hr}$ of cooling after which they were transferred to room temperature water until the test for savings. The animals that received a memory reactivation session in conjunction with cooling did not demonstrate memory, whereas the group that received the cooling alone $\operatorname{did}\left(F_{(32,5)}=26.189 ; p<\right.$ 0.0001 ).

The test for savings for those animals that received the memory reactivation session (Fig. $2 A)$ was significantly higher $(p<$ 0.01 ) than the test for savings for the group that did not receive a memory reactivation session (Fig. $2 \mathrm{~B}$ ). The animals that received a memory reactivation session before the cooling did not dem-

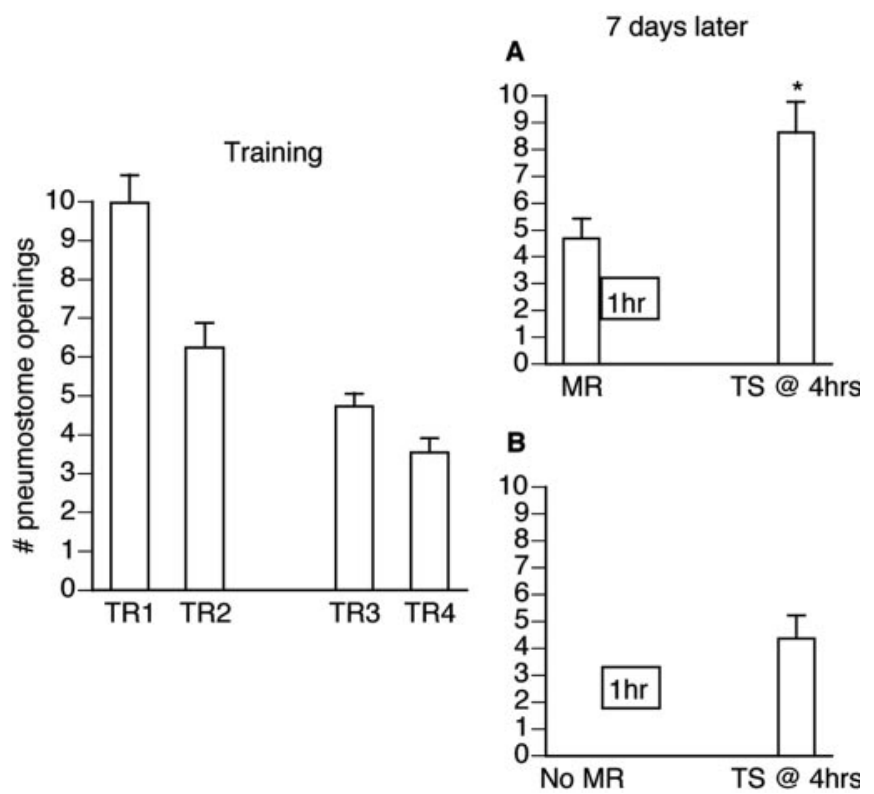

Figure 2. Cooling blocks the reconsolidation of a memory that has been reactivated. Operant training was administered (TR1-TR4) over the course of $2 \mathrm{~d}(n=33)$. Then $7 \mathrm{~d}$ later 19 animals received a MR session ( $A$ ), immediately followed by $1 \mathrm{hr}$ of cooling (denoted by box), whereas the remaining animals $(B ; n=14)$ received only the $1 \mathrm{hr}$ of cooling. The group that received a MR session in conjunction with cooling did not demonstrate memory as tested $4 \mathrm{hr}$ later. The remaining animals that did not receive a MR session but still received $1 \mathrm{hr}$ of cooling still demonstrated memory during the test for savings; ${ }^{*} p<0.01$ as compared with MR.

onstrate memory during the test for savings. The test for savings was not significantly different $(p>0.05)$ from the first training session and was significantly higher $(p<0.01)$ than the last training session, thus not meeting the criteria for memory designation. In contrast, the second group, which did not receive a memory reactivation session, did show memory during the test for savings. The test for savings was significantly lower $(p<0.01)$ than the first training session and not significantly different $(p>$ 0.05 ) from the last training session.

These data imply that, within the first hour after memory reactivation, the memory is susceptible to a technique commonly used to interfere with the consolidation phase in the formation of an LTM.

\section{The reconsolidation process requires RNA synthesis}

Several laboratories have shown the need for new RNA synthesis in the formation of new long-term memories (Sangha et al., 2003a) (for review, see Davis and Squire, 1984). Here the commonly used RNA synthesis blocker actinomycin D was injected systemically into the snail immediately after memory reactivation.

Snails $(n=55)$ were conditioned operantly, as outlined in Materials and Methods. Then $7 \mathrm{~d}$ later the animals were divided randomly into two groups (Fig. 3). The first group (Fig. $3 A ; n=$ $29)$ received a memory reactivation session immediately followed by either an actinomycin $\mathrm{D}(n=16)$ or saline $(n=13)$ injection. The second group (Fig. $3 B ; n=26$ ) did not receive a memory reactivation session but still were administered either an actinomycin $\mathrm{D}(n=12)$ or saline $(n=14)$ injection. A single mixed design ANOVA was performed to test two between-group factors (i.e., Factor I, MR vs NoMR; Factor II, actinomycin D vs saline) and a within-group factor (i.e., training sessions vs tests for savings). The ANOVA was significant $\left(F_{(54,7)}=80.015 ; p<0.0001\right)$, 

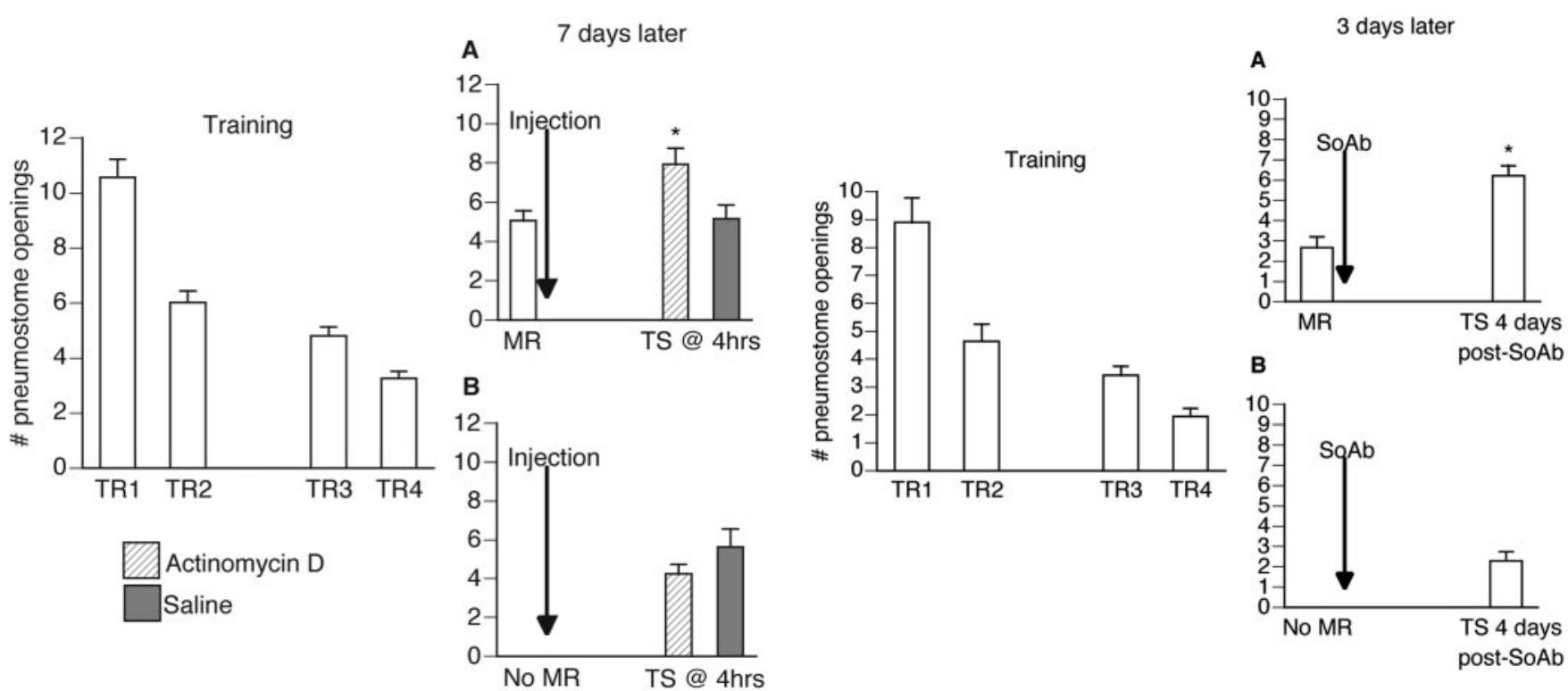

Figure 3. Actinomycin D blocks the reconsolidation of a memory that has been reactivated. Operant training was administered (TR1-TR4) over the course of $2 \mathrm{~d}(n=55)$. Then $7 \mathrm{~d}$ later 29 animals received a MR session $(A)$, immediately followed by an injection of either $\operatorname{ActD}(n=16)$ or saline $(n=13)$. The remaining animals $(n=26)$ did not receive a MR session $(B)$ but still were administered either ActD $(n=12)$ or saline $(n=14)$. The group that received a MR session in conjunction with ActD did not demonstrate memory as tested $4 \mathrm{hr}$ later. Salineinjected animals that also received a MR session did show memory $4 \mathrm{hr}$ later. The remaining animals did not receive a MR session but still were injected with either $A c t D(n=12)$ or saline $(n=14)$. Both groups showed memory 4 hr later during the test for savings; ${ }^{*} p<0.01$ as compared with MR.

thus a post hoc Scheffe's comparison was performed to show which groups and sessions were significantly different.

The first group (Fig. $3 A ; n=29$ ) received a memory reactivation session in which they demonstrated memory. The memory reactivation session was significantly lower $(p<0.01)$ than the first training session, and, although it was also significantly higher $(p<0.01)$ than the last training session, it was not significantly higher $(p>0.05)$ than either the second or third training sessions. Immediately after the memory reactivation session the animals were injected with either actinomycin $\mathrm{D}(n=16)$ or saline $(n=13)$. A test for savings was administered to all of these animals $4 \mathrm{hr}$ after the memory reactivation session. The test for savings for animals that received a memory reactivation session in conjunction with an actinomycin D injection was significantly higher $(p<0.01)$ than the test for savings for all other groups. Animals injected with actinomycin D did not demonstrate memory during the test for savings; the test for savings was significantly different $(p<0.01)$ from both the first and last training sessions, thus not meeting the criteria for memory designation. Animals injected with saline did demonstrate memory during the test for savings; the test for savings was significantly lower $(p<$ $0.01)$ than the first training session and not significantly different $(p>0.05)$ from the last training session. Thus actinomycin D effectively blocked the reconsolidation process.

The second group (Fig. $3 B ; n=26$ ) did not receive a memory reactivation session but did receive either an actinomycin $\mathrm{D}(n=$ 12 ) or saline $(n=14)$ injection at the same time as the first group. A test for savings was administered $4 \mathrm{hr}$ later. The tests for savings for these two sets of animals were not significantly different $(p>$ 0.05 ) from each other. Both actinomycin D-injected and salineinjected animals demonstrated memory during the test for sav-

Figure 4. Soma of RPeD1 is required for reconsolidation. Operant training was administered (TR1-TR4) over the course of $2 \mathrm{~d}(n=19)$. Then $3 \mathrm{~d}$ later nine animals received a MR session $(A)$, immediately followed by the ablation of the soma of RPeD1 ( $\mathrm{SoAb})$, whereas the remaining animals $(B ; n=10)$ did not receive a MR session but still underwent the ablation procedure. Animals were tested for savings $4 \mathrm{~d}$ later. Memory was not observed in the group that received the MR session in conjunction with the ablation procedure. Memory was observed in the other soma-ablated group, the one that did not receive a MR session; $p<0.01$ as compared with MR.

ings. The test for savings for both sets of animals was significantly lower $(p<0.01)$ than the first training session and not significantly different $(p>0.05)$ from the last training session.

In summary, this experiment demonstrates that, if RNA synthesis is blocked immediately after memory reactivation during the "hypothesized" reconsolidation process, memory will not be observed 4 hr later.

\section{The soma of RPeD1 is required for reconsolidation}

We have shown previously that the soma of RPeD1 is necessary for the consolidation and formation of a new long-term nondeclarative memory (Scheibenstock et al., 2002). By ablating the soma of RPeD1, we are removing the nucleus of this cell and thus inhibiting RNA synthesis. Protein synthesis still can occur in the remaining neurite (Spencer et al., 2000). Here we investigate whether the soma also is required in reconsolidating a long-term memory.

Snails $(n=19)$ were conditioned operantly as outlined in Materials and Methods. Then $3 \mathrm{~d}$ later the animals were divided randomly into two groups (Fig. 4). The first group (Fig. 4A;n= 9) received a memory reactivation session immediately followed by RPeD1 soma ablation. The second group (Fig. $4 B ; n=10$ ) also received the $\mathrm{RPeD} 1$ soma ablation procedure but did not receive a memory reactivation session. The animals that received a memory reactivation session in conjunction with the ablation did not demonstrate memory, whereas the group that received the ablation alone $\operatorname{did}\left(F_{(18,5)}=37.265 ; p<0.0001\right)$.

The first group (Fig. $4 A ; n=9$ ) received a memory reactivation session and demonstrated memory. The memory reactivation session was significantly lower $(p<0.01)$ than the first training session and not significantly different $(p>0.05)$ from the last training session, thus meeting both criteria for memory designation. Immediately after the memory reactivation session the soma of RPeD1 was ablated. Animals were given $4 \mathrm{~d}$ for full surgical recovery and were administered a test for savings. The 
test for savings revealed that these animals did not exhibit memory; the test for savings was significantly different $(p<0.01)$ from both the first and last training sessions, thus not meeting the criteria for memory designation.

The second group (Fig. $4 B ; n=10$ ) did not receive a memory reactivation session $3 \mathrm{~d}$ later; however, the animals still underwent the RPeD1 soma ablation procedure. Similar to the first group, these animals also were given $4 \mathrm{~d}$ for full surgical recovery before a test for savings was administered. These animals, in contrast to the first group, did exhibit memory during the test for savings. The test for savings was significantly less $(p<0.01)$ than the first training session and not significantly different $(p>0.05)$ from the last training session.

In summary, this experiment reveals that the soma of RPeD1 is necessary for reconsolidation. We have shown previously (Scheibenstock et al., 2002) that the ablation of this soma before training prevents the formation of new long-term memories. Thus both consolidation and reconsolidation of an LTM in Lymnaea require the soma of $\mathrm{RPeD} 1$.

\section{Discussion}

In this paper we presented data consistent with the hypothesis that after memory reactivation there is a reconsolidation process that must occur to preserve the memory. That is, when a memory is reactivated, it enters a labile state and must undergo a process to stabilize it again (i.e., reconsolidation). We found that this reconsolidation process could be interrupted by cooling, by the RNA synthesis blocker actinomycin $\mathrm{D}$, and by ablating the soma of $\mathrm{RPeD} 1$. Each of these procedures disrupted the reconsolidation process only when they were applied immediately after memory reactivation. That is, memory impairment was seen only in those animals in which the memory was reactivated just before the treatment that was used. The data presented here are consistent with other findings that amnesiac treatments have an effect only when applied during or immediately after memory reactivation (Nader et al., 2000; Anokhin et al., 2002; Debiec et al., 2002; Kida et al., 2002; Milekic and Alberini, 2002; Pedreira et al., 2002). This indicates that memories can exist in an active, labile, disturbable state or in an inactive, stable state (Lewis, 1979).

Why does a recently activated memory enter a labile, potentially disruptive state? The reconsolidation process may provide a dynamic mechanism by which memories can be updated and changed to better fit current environmental circumstances (Nader, 2003). The current literature suggests that, when a memory is reactivated by stimuli associated with learning, there is a reenactment of at least some of the cellular events that occur during the initial consolidation (Sara, 2000). Those memories that have not been recalled recently are stably encoded, but active memories may be altered in the interest of incorporating new information available at the time of recall (Sara, 2000). Because "the only proof of there being retention is that recall actually takes place" (James, 1890), what may be critical is not the original consolidation of newly acquired information but, rather, further integration of this information into aspects of other memories or behavioral representations (Sara, 2000). However, the "updating" of memory may have consequences on the accuracy of memory, for example, the phenomenon of "false memory" (Thomas and Loftus, 2002) or "misattribution" (Schacter and Dodson, 2001).

Is reconsolidation the recapitulation of molecular events that occur during consolidation? There are several lines of evidence implying that initial memory formation and reconsolidation use similar pathways. For instance, the requirement for NMDA re- ceptors in consolidation has been shown in a variety of learning paradigms (Morris et al., 1986; Abeliovich et al., 1993; Bourtchouladze et al., 1994) and also has been reported to be necessary during reconsolidation in rats (Przybyslawski and Sara, 1997), chicks (Summers et al., 1997), and the crab (Pedreira et al., 2002). A late $\beta$-adrenergic receptor-dependent phase also has been described for both consolidation and reconsolidation (Roullet and Sara, 1998; Przybyslawski et al., 1999; Sara et al., 1999; Sara, 2000). In addition, CREB has been reported to be necessary for consolidation (Dash et al., 1990; Bourtchouladze et al., 1994; Yin et al., 1994; Guzowski and McGaugh, 1997; Kogan et al., 1997; Lamprecht et al., 1997) and reconsolidation (Kida et al., 2002). Finally, the necessity of new protein synthesis during consolidation (for review, see Davis and Squire, 1984; Dudai, 1989; Squire and Kandel, 1999) and in the restabilization of a memory after memory reactivation also has been demonstrated (Nader et al., 2000; Anokhin et al., 2002; Debiec et al., 2002; Kida et al., 2002; Milekic and Alberini, 2002; Pedreira et al., 2002). Some studies have disrupted reconsolidation after inhibiting protein synthesis in the same brain regions that require protein synthesis during the original learning (Nader et al., 2000; Debiec et al., 2002).

The data presented here are consistent with the reports in vertebrate models (Debiec et al., 2002; Kida et al., 2002; Milekic and Alberini, 2002) that new RNA and protein synthesis are required for the reconsolidation process. We accomplished this via two ways, by administering $1 \mathrm{hr}$ of cooling or by injecting actinomycin D immediately after memory reactivation. The disruption in memory reconsolidation was evident only if the memory was reactivated before treatment. We have seen a similar effect on LTM consolidation when either actinomycin D or cooling is administered immediately after initial training (Sangha et al., 2003a,b). We also were able to prevent reconsolidation by removal of the soma of RPeD1 immediately after reactivation of the memory. The soma of RPeD1 is necessary for the initial consolidation process by which learning is embedded into LTM (Scheibenstock et al., 2002). However, RPeD1 soma-ablated snails are still capable of associative learning and the formation of ITM, which persists for up to 3-4 hr (Scheibenstock et al., 2002). ITM, although dependent on new protein synthesis, is not dependent on altered gene activity (Rosenzweig et al., 1993; Sangha et al., 2003a). Thus all of our data support the hypothesis that reconsolidation of an LTM in Lymnaea is dependent on both altered gene activity and new protein synthesis. Our data also show that the soma of RPeD1 is necessary for both the initial consolidation process and the reconsolidation process. As discussed below, whether the soma of RPeD1 will be necessary for memory that has undergone repeated reconsolidation can be determined directly in the future.

One reported difference in the process of consolidation versus reconsolidation is in the role of the CCAAT-enhancing binding protein $(\mathrm{C} / \mathrm{EBP}) . \mathrm{C} / \mathrm{EBP} \beta$, a protein downstream of $\mathrm{CREB}$, is believed to activate the transcription of late genes essential for the consolidation of memory, because it has been shown to be induced during the consolidation of a long-term memory in both Aplysia (Alberini et al., 1994) and rats (Taubenfeld et al., 2001). In addition, Lee et al. (2001) demonstrated that Aplysia sensory cells that overexpress C/EBP could display long-term facilitation with only a short-term facilitation-inducing protocol. Taubenfeld et al. (2001) have reported that, although $\mathrm{C} / \mathrm{EBP} \beta$ is activated during memory consolidation, it does not appear to be a necessary event in reconsolidation. Collectively, the current data suggest that the sequence of events that are initiated in both consolidation and reconsolidation may converge on the activation of 
CREB but then subsequently diverge into separate and unique pathways. It is possible that this divergence in the molecular pathway for reconsolidation versus consolidation exists because the neural circuit for the storage of declarative memory, the type studied in the Taubenfeld et al. (2001) study, is different from the neural circuit that mediates the learned behavior (Milner et al., 1998). It may be that in nondeclarative memory, the type studied here, such a divergence will not exist. This hypothesis needs to be tested directly and may show molecular differences between the molecular substrates of declarative versus nondeclarative memory.

Our data are consistent with this view because all treatments used in this paper prevented either gene activation or the events downstream of gene activation, namely new protein synthesis from preexisting mRNA. Using the RPeD1 soma ablation technique, we demonstrate that the soma of this particular cell is required for reconsolidation. To our knowledge this is the first demonstration that a single neuron is a necessary site for the reconsolidation process. It is imperative to note that the soma ablation procedure leaves behind a functional neurite in which local protein synthesis still can occur (Spencer et al., 2000). Thus new protein synthesis from preexisting mRNA, although a necessary step, is not sufficient to restabilize a recently reactivated memory successfully.

It would be more efficient for a system to have newer memories be dependent on new protein synthesis and be labile but, eventually, after the memory has been reactivated several times, be protein synthesis-independent and more resistant to change. One possibility could be that during reactivation a given number of the same newly formed synapses are reengaged and subsequently destabilized and reorganized to incorporate new information (Milekic and Alberini, 2002). Mathematical modeling suggests that the memory span could increase dramatically if there is a decrease in the fraction of synapses that are changed on each stimulus presentation (Fusi, 2002). This supports the hypothesis that, on several reactivation episodes, a memory eventually would become independent of new RNA and protein synthesis and instead be resistant to further change. It might be possible in the future to test this hypothesis directly in our model system by repeatedly activating the operantly conditioned-induced memory and then ablating the soma of RPeD1 or applying cooling and then testing whether or not the reconsolidation process still requires altered gene activity or new protein synthesis.

\section{References}

Abeliovich A, Paylor R, Chen C, Kim JJ, Wehner JM, Tonegawa S (1993) PKC $\gamma$ mutant mice exhibit mild deficits in spatial and contextual learning. Cell 75:1263-1271.

Alberini CM, Ghirardi M, Metz R, Kandel ER (1994) C/EBP is an immediate-early gene required for the consolidation of long-term facilitation in Aplysia. Cell 76:1099-1114.

Anokhin KV, Tiunova AA, Rose SP (2002) Reminder effects-reconsolidation or retrieval deficit? Pharmacological dissection with protein synthesis inhibitors following reminder for a passive-avoidance task in young chicks. Eur J Neurosci 15:1759-1765.

Bourtchouladze R, Frenguelli B, Blendy J, Cioffi D, Schutz G, Silva AJ (1994) Deficient long-term memory in mice with a targeted mutation of the cAMP-responsive element-binding protein. Cell 79:59-68.

Cartford MC, Gohl EB, Singson M, Lavond DG (1997) The effects of reversible inactivation of the red nucleus on learning-related and auditoryevoked unit activity in the pontine nuclei of classically conditioned rabbits. Learn Mem 3:519-531.

Dash PK, Hochner B, Kandel ER (1990) Injection of the cAMP responsive element into the nucleus of Aplysia sensory neurons blocks long-term facilitation. Nature 345:718-721.
Davis HP, Squire LR (1984) Protein synthesis and memory: a review. Psychol Bull 96:518-559.

Debiec J, LeDoux JE, Nader K (2002) Cellular and systems reconsolidation in the hippocampus. Neuron 36:527-538.

Dudai Y (1989) The neurobiology of memory: concepts, findings, trends. Oxford: Oxford UP.

Feng Z, Klumperman J, Lukowiak K, Syed N (1997) In vitro synaptogenesis between somata of identified Lymnaea neurons requires protein synthesis but not extrinsic growth factors or substrate adhesion molecules. J Neurosci 17:7839-7849.

Fusi S (2002) Hebbian spike-driven synaptic plasticity for learning patterns of mean firing rates. Biol Cybern 87:459-470.

Guzowski JE, McGaugh JL (1997) Antisense oligodeoxynucleotidemediated disruption of hippocampal cAMP response element binding protein levels impairs consolidation of memory for water maze training. Proc Natl Acad Sci USA 94:2693-2698.

Hamakawa T, Woodin MA, Bjorgum MC, Painter SD, Takasaki M, Lukowiak K, Nagle GT, Syed NI (1999) Excitatory synaptogenesis between identified Lymnaea neurons requires extrinsic trophic factors and is mediated by receptor tyrosine kinases. J Neurosci 19:9306-9312.

James W (1890) The principles of psychology. New York: Holt.

Judge ME, Quartermain D (1982) Characteristics of retrograde amnesia following reactivation of memory in mice. Physiol Behav 28:585-590.

Kida S, Josselyn SA, Pena de Ortiz S, Kogan JH, Chever I, Masushige S, Silva AJ (2002) CREB required for the stability of new and reactivated fear memories. Nat Neurosci 5:348-355.

Kogan JH, Frankland PW, Blendy JA, Coblentz J, Marowitz Z, Schutz G, Silva AJ (1997) Spaced training induces normal long-term memory in CREB mutant mice. Curr Biol 7:1-11.

Lamprecht R, Hazvi S, Dudai Y (1997) cAMP response element binding protein in the amygdala is required for long- but not short-term conditioned taste aversion memory. J Neurosci 17:8443-8450.

Lee JL, Kim H, Kim K, Han J, Lee Y, Lim C, Chang D, Kubo T, Kaang B (2001) Overexpression of and RNA interference with the CCAAT enhancer-binding protein on long-term facilitation of Aplysia sensory to motor synapses. Learn Mem 8:220-226.

Lewis DJ (1979) Psychobiology of active and inactive memory. Psychol Bull 86:1054-1083.

Lukowiak K, Ringseis E, Spencer G, Wildering W, Syed N (1996) Operant conditioning of aerial respiratory behaviour in Lymnaea stagnalis. J Exp Biol 199:683-691.

Lukowiak K, Cotter R, Westley J, Ringseis E, Spencer G, Syed N (1998) Long-term memory of an operantly conditioned respiratory behaviour in Lymnaea stagnalis. J Exp Biol 201:877-882.

Lukowiak K, Adatia A, Krygier D, Syed N (2000) Operant conditioning in Lymnaea: evidence for intermediate and long-term memory. Learn Mem 7:140-150.

Lukowiak K, Haque Z, Spencer G, Varshay N, Sangha S, Syed N (2003a) Long-term memory survives nerve injury and the subsequent regeneration process. Learn Mem 10:44-54.

Lukowiak K, Sangha S, McComb C, Varshney N, Rosenegger D, Sadamoto H, Scheibenstock A (2003b) Associative learning and memory in Lymnaea stagnalis: how well do they remember? J Exp Biol 206:2097-2103.

Milekic MH, Alberini CM (2002) Temporally graded requirement for protein synthesis following memory reactivation. Neuron 36:521-525.

Milner B, Squire LR, Kandel ER (1998) Cognitive neuroscience and the study of memory. Neuron 20:445-468.

Misanin JR, Miller RR, Lewis DJ (1968) Retrograde amnesia produced by electroconvulsive shock after reactivation of a consolidated memory trace. Science 160:203-204.

Morris RG, Anderson E, Lynch GS, Baudry M (1986) Selective impairment of learning and blockade of long-term potentiation by an $\mathrm{N}$-methyl-Daspartate receptor antagonist, AP5. Nature 319:774-776.

Morrison GE, van der Kooy D (1997) Cooling before associative conditioning blocks memory retrieval, but cooling after conditioning blocks memory retention in Caenorhabditis elegans. Behav Neurosci 111:564-578.

Muller GE, Pilzecker A (1900) Experimentelle Beitrage zur Lehre von Gedachtnis. Z Psychol Suppl 1:1-300.

Nader K (2003) Memory traces unbound. Trends Neurosci 26:65-72.

Nader K, Schafe GE, LeDoux JE (2000) Fear memories require protein synthesis in the amygdala for reconsolidation after retrieval. Nature 406:722-726. 
Pedreira ME, Perez-Cuesta LM, Maldonado H (2002) Reactivation and reconsolidation of long-term memory in the crab Chasmagnathus: protein synthesis requirement and mediation by NMDA-type glutamatergic receptors. J Neurosci 22:8305-8311.

Przybyslawski J, Sara SJ (1997) Reconsolidation of memory after its reactivation. Behav Brain Res 84:241-246.

Przybyslawski J, Roullet P, Sara SJ (1999) Attentuation of emotional and nonemotional memories after their reactivation: role of $\beta$-adrenergic receptors. J Neurosci 19:6623-6628.

Ribot T (1882) Diseases of memory. New York: Appleton-Century-Crofts.

Rosenzweig M, Bennett E, Colombo P, Lee D, Serrano P (1993) Short-term, intermediate term, and long-term memories. Behav Brain Res 57:193-198.

Roullet P, Sara SJ (1998) Consolidation of memory after its reactivation: involvement of $\beta$-noradrenergic receptors in the late phase. Neural Plast 6:63-68.

Sangha S, Scheibenstock A, McComb C, Lukowiak K (2003a) Intermediate and long-term memories of associative learning are differentially affected by transcription vs translation blockers in Lymnaea. J Exp Biol 206:1605-1613.

Sangha S, Morrow R, Smyth K, Cooke R, Lukowiak K (2003b) Cooling blocks ITM and LTM formation and preserves memory. Neurobiol Learn Mem, in press.

Sara SJ (2000) Retrieval and reconsolidation: toward a neurobiology of remembering. Learn Mem 7:73-84.

Sara SJ, Roullet P, Przybyslawski J (1999) Consolidation of memory for odor-reward association: $\beta$-adrenergic receptor involvement in the late phase. Learn Mem 6:88-96.

Schacter D, Dodson C (2001) Misattribution, false recognition, and the sins of memory. Philos Trans R Soc Lond B Biol Sci 356:1385-1393.

Scheibenstock A, Krygier D, Haque Z, Syed N, Lukowiak K (2002) The soma of RPeD1 must be present for LTM formation of associative learning in Lymnaea. J Neurophysiol 88:1584-1591.

Sekiguchi T, Yamada A, Suzuki H (1997) Reactivation-dependent changes in memory states in the terrestrial slug Limax flavus. Learn Mem 4:356-364.

Spencer GE, Syed N, Lukowiak K (1999) Neural changes after operant con- ditioning of the aerial respiratory behavior in Lymnaea stagnalis. J Neurosci 19:1836-1843.

Spencer GE, Syed NI, van Kesteren E, Lukowiak K, Geraerts WPM, van Minnen J (2000) Synthesis and functional integration of a neurotransmitter receptor in isolated invertebrate axons. J Neurobiol 44:72-81.

Spencer GE, Kazmi M, Syed N, Lukowiak K (2002) Changes in the activity of a central pattern generator neuron following the reinforcement of an operantly conditioned behavior in Lymnaea. J Neurophysiol 88:1915-1923.

Squire LR, Kandel ER (1999) Memory: from mind to molecules. New York: Scientific American Library.

Summers MJ, Crowe SF, Ng KT (1997) Administration of D,L-2-amino-5phosphonovaleric acid (AP5) induces transient inhibition of reminderactivated memory retrieval in day-old chicks. Brain Res Cogn Brain Res 5:311-321.

Syed NI, Bulloch AGM, Lukowiak K (1990) In vitro reconstruction of the respiratory central pattern generator of the mollusk Lymnaea. Science 250:282-285.

Syed NI, Ridgway R, Lukowiak K, Bulloch AGM (1992) Transplantation and functional integration of an identified respiratory interneuron in Lymnaea stagnalis. Neuron 8:767-774.

Taubenfeld SM, Milekic MH, Monti B, Alberini CM (2001) The consolidation of new but not reactivated memory requires hippocampal C/EBP $\beta$. Nat Neurosci 4:813-818.

Thomas A, Loftus E (2002) Creating bizarre false memories through imagination. Mem Cognit 30:423-431.

van Minnen J, Bergman E, Van Kesteren R, Smit A, Geraerts W, Lukowiak K, Hasan S, Syed N (1997) De novo protein synthesis in isolated axons. Neuroscience 80:1-7.

Yamada A, Sekiguchi T, Suzuki H, Mizukami A (1992) Behavioral analysis of internal memory states using cooling-induced retrograde amnesia in Limax flavus. J Neurosci 12:729-735.

Yin JC, Wallach JS, Del Vecchio M, Wilder EL, Zhou H, Quinn WG, Tully T (1994) Induction of a dominant negative CREB transgene specifically blocks long-term memory in Drosophila. Cell 79:49-58.

Zar JH (1999) Biostatistical analysis, 3rd Ed. Upper Saddle River, NJ: Prentice-Hall. 